See discussions, stats, and author profiles for this publication at: https://www.researchgate.net/publication/343677978

Regional variations and socio-economic disparities in neonatal mortality in Angola: A cross-sectional study using demographic and health surveys

Article in Family Practice · August 2020

DOI: 10.1093/fampra/cmaa083

\section{CITATIONS}

0

5 authors, including:

Sanni Yaya

University of Ottawa

349 PUBLICATIONS 2,778 CITATIONS

SEE PROFILE

Bright Opoku Ahinkorah

University of Technology Sydney

145 PUBLICATIONS 313 CITATIONS

SEE PROFILE
READS

282

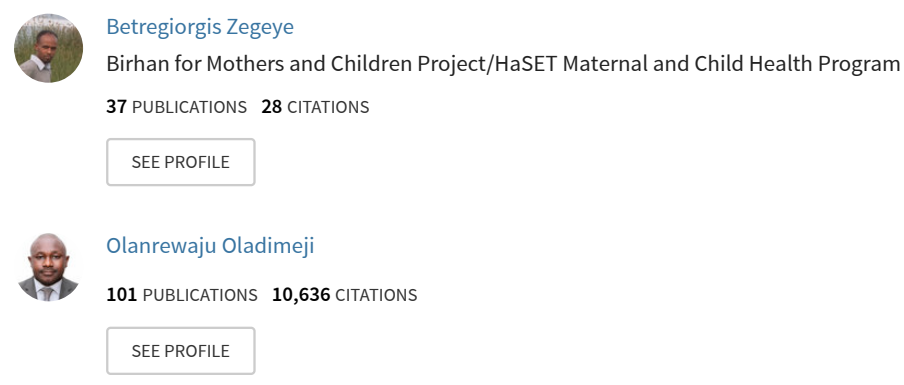

Some of the authors of this publication are also working on these related projects:

South African national HIV prevalence, incidence, behaviour and com munication survey (SABSSM V) View project

council View project 


\title{
Regional variations and socio-economic disparities in neonatal mortality in Angola: a cross-sectional study using demographic and health surveys
}

\author{
Sanni Yaya a,b,*, , Betregiorgis Zegeye ${ }^{c}$, Bright Opoku Ahinkorah ${ }^{d}$, \\ Olanrewaju Oladimejie,f,g and Gebretsadik Shibre ${ }^{h}$
}

aSchool of International Development and Global Studies, University of Ottawa, Ottawa, Canada, ${ }^{\mathrm{b} T h e}$ George Institute for Global Health, The University of Oxford, Oxford, UK, 'HaSET Maternal and Child Health Research Program, Shewarobit Field Office, Shewarobit, Ethiopia, 'The Australian Centre for Public and Population Health Research, Faculty of Health, University of Technology Sydney, Sydney, NSW, Australia, ${ }^{e}$ Department of Public Health, Walter Sisulu University, Eastern Cape, South Africa, ${ }^{f}$ Center for Community Healthcare, Research and Development, Abuja, Nigeria, ${ }^{9}$ Faculty of Health Sciences, Durban University of Technology, Durban, South Africa and 'Department of Reproductive, Family and Population Health, School of Public Health, Addis Ababa University, Addis Ababa, Ethiopia

*Correspondence to Sanni Yaya, School of International Development and Global Studies, University of Ottawa, 120 University Private, Ottawa, Ontario K1N 6N5, Canada; E-mail: sanni.yaya@uottawa.ca

\begin{abstract}
Background: Inequalities in neonatal mortality rates (NMRs) in low- and middle-income countries show key disparities at the detriment of disadvantaged population subgroups. There is a lack of scholarly evidence on the extent and reasons for the inequalities in NMRs in Angola.

Objective: The aim of this study was to assess the socio-economic, place of residence, region and gender inequalities in the NMRs in Angola.

Methods: The World Health Organization Health Equity Assessment Toolkit software was used to analyse data from the 2015 Angola Demographic and Health Survey. Five equity stratifiers: subnational regions, education, wealth, residence and sex were used to disaggregate NMR inequality. Absolute and relative inequality measures, namely, difference, population attributable fraction (PAF), population attributable risk (PAR) and ratio, were calculated to provide a broader understanding of the inequalities in NMR. Statistical significance was calculated at corresponding 95\% uncertainty intervals.

Findings: We found significant wealth-driven [PAR $=-14.16,95 \%$ corresponding interval $(\mathrm{CI}):-15.12$, -13.19], education-related (PAF $=-22.5 \%, 95 \% \mathrm{Cl}:-25.93,-19.23)$, urban-rural (PAF $=-14.5 \%$, 95\% Cl: $-16.38,-12.74$ ), sex-based (PAR $=-5.6 \%, 95 \% \mathrm{Cl}:-6.17,-5.10$ ) and subnational regional (PAF $=-82.2 \%, 95 \% \mathrm{Cl}:-90.14,-74.41)$ disparities in NMRs, with higher burden among deprived population subgroups.

Conclusions: High NMRs were found among male neonates and those born to mothers with no formal education, poor mothers and those living in rural areas and the Benguela region. Interventions aimed at reducing NMRs, should be designed with specific focus on disadvantaged subpopulations.
\end{abstract}

Keywords: Angola, demographic and health surveys, global health, health disparities, neonatal mortality, sub-Saharan Africa. 


\section{Key Messages \\ - Neonatal mortality is an important indicator of population health. \\ - There are many factors contributing to disparities in neonatal mortality. \\ - Neonatal mortality elimination requires multifaceted interventions.}

\section{Background}

The neonatal period-the first 28 days of life-is a significant and crucial period in the life of a newborn and plays a key role in determining the survival of the child (1). In $2018,50 \%$ of all under-5 deaths occurred during the neonatal period globally. Specifically, under-5 mortality in 2018 was 39 deaths per 1000 live births, while neonatal mortality rate (NMR) was 18 deaths per 1000 live births (2). Hence, the neonatal period is considered as the period when children face the highest risk of dying (3). Although the global rate of neonatal mortality decreased from 37 deaths per 1000 live births in 1990 to 19 in 2018, the reduction in neonatal deaths during this period was lower $(49 \%)$ compared to the reduction in deaths among children aged 1-59 months (62\%) (2). In 2018, Southern Asia and sub-Saharan Africa (SSA) accounted for close to $80 \%$ of newborn deaths, with $39 \%$ of neonatal deaths recorded in Southern Asia and $38 \%$ in SSA (2). In 2018, about 35780 newborns died within the first 28 days of birth in Angola (2).

Generally, there has been an increase in effective interventions aimed at improving the survival rate of neonates globally. These include early initiation of breastfeeding, provision and promotion of the use of insecticide-treated nets (ITNs) for children, antenatal care, tetanus immunization in pregnancy, prophylactic antimalarials during pregnancy, induction of labour for prolonged pregnancy and case management of childhood malaria and pneumonia (4). Nonetheless, what remains a challenge is the actual implementation of these essential strategies, especially in low- and middle-income countries (5) where majority of neonatal deaths occur (6). Evidence suggest disproportionate access to these health care interventions in these countries $(7,8)$, while other studies have indicated socio-economic disparities in neonatal deaths, with the most affected groups being the poor, illiterates and rural dwellers $(5,9)$. To help enhance the achievement of an equity-based international strategy to meet the sustainable development goals, there is the need for evidence-based research that provide information on neonatal deaths and address the disparities in its distribution over time.

Angola's health system comprises of two major divisions, primary health, a community-level preventative service, and acute care, hospital services for complex treatments. The health system is under-resourced with more than $50 \%$ of the population not having access to health services. The quality of available health services and their coverage are both severely limited and public health programmes are overstretched. In the whole country, there is one health centre per 25000 persons, one pharmacy per 22500 persons, one maternity bed per 577 births and one paediatric bed per 13540 children under 15 years of age. The ratios vary depending on the region, and very populous areas, such as Maradi, Tahoua, Zinder and Tillaberi, are the least covered (10). A World Health Organization (WHO) report indicates that the health needs and problems in Angola include insufficient coverage and poor maintenance of health centres; poor referral; limited health personnel and poor distribution of personnel in rural and peri-urban areas (11). These disparities have been found to contribute to low utilization of maternal health care services (12), malnutrition (13) and child and maternal mortality $(12,14)$.
To reduce NMR and enhance the survival of newborns, the WHO recommends a reduction in inequity through the universal health coverage principles, including dealing with the needs of newborns in humanitarian and fragile settings (15). Measuring inequalities between population subgroups based on relevant dimensions of variation (i.e. demographic, socio-economic or geographical factors) is vital for understanding how policies, programs and practices can be aligned to enhance better health in disadvantaged populations (16). However, no study has been carried out in Angola to assess the socio-economic inequalities in NMR.

This study, therefore, aims to enrich the available evidence by providing a holistic understanding of NMR. First, using the WHO Health Inequality Monitoring Handbook, we investigated NMR inequality through different dimensions of inequality measures (17). In doing this, we calculated commonly used simple means of absolute [difference (D)] and relative [ratio (R)], as well as complex, inequality measures [population attributable risk (PAR) and population attributable fraction (PAF)] to reflect the magnitude and proportion of the difference between the subgroups studied (17). Second, based on WHO's recommendation, we used five equity stratifiers to account for several dimensions of inequality to study subgroup differences (17).

\section{Method}

\section{Data sources}

Data for this study was obtained from the 2015 Angola Demographic and Health Survey (ADHS). Detailed information on the ADHS methodology has been provided elsewhere (18). Briefly, a two-stage cluster design was used to select women aged 15-49. In the first stage, census areas, known as enumeration areas (EAs), are selected through probability proportional to their size; the larger the EA (EA that has large number of households), the higher the probability of that EA to be included in the sample. The census EA serves as a primary sampling unit or cluster variable in the data set. Once EAs are selected, then a fixed number of households are selected via a systematic sampling scheme from each EA, the process that constitutes the second stage of the design.

DHS surveys are nationally representative and collects a wide range of public health-related information and data, including maternal and child mortality. Financial and technical support for the survey were obtained from the he Inner-City Fund (ICF) International and provided through the MEASURE DHS program financed by United States Agency for International Agency.

\section{Selection of variables}

The key outcome variable was inequality in NMR. NMR refers to the probability of deaths in a child born at a specific time within the first 30 days of life per 1000 live births. This information is available in the DHS through the history of birth, which gathers information on the date of birth and the age of death of the neonate. Data on live births that occurred 5 years prior to the survey were included in the analysis. 


\section{Measures}

Five equity stratifiers: subnational regions, educational, wealth, residence and sex were used to disaggregate NMR inequality. These were selected based on their relevance in previous studies $(19,20)$ and their availability in the WHO Health Inequality Monitoring Handbook (17). Wealth index, calculated on the basis of household assets and household characteristics, was used to approximate the financial situation. In DHS, the principal component analysis is used to calculate wealth index and is classified into: the poorest, the poor, the middle, the rich and the richest. The educational status of the mother was grouped as non-educational, primary and secondary education. Place of residence is classified as urban versus rural, 18 regions were used to categorize subnational regions and neonate sex was classified as male and female.

\section{Statistical analysis}

Inequality in the NMR was examined in two steps. The first step involved the disaggregation of NMR by the five equity stratifiers mentioned above. Second, we assessed inequality using four measure of inequality: D, PAR, PAF and R. Whereas PAF and R are complex measures, $\mathrm{D}$ and $\mathrm{R}$ are simple measures. $\mathrm{R}$ and PAF are relative measures, while D and PAR are absolute summary measures. The summary measures were chosen based on evidence that both absolute and relative measures are of scientific importance in a single health inequalities study (17). Simple measures are easy to interpret and understand. In contrast, complex measures account for the size of subpopulation of categories and are reasonable to reflect real change in inequality over time, especially when population shifts are likely to occur (17). To provide a more comprehensive analysis in inequality studies, it is essential to combine both simple and complex, as well as relative and absolute, measures.

The WHO Health Equity Assessment Toolkit (HEAT) version 3.1 software was used to perform the analyses (21). In calculating the summary measures, the procedures followed are discussed in the HEAT Software Technical Notes (21) and the WHO Health Inequality Monitoring Handbook (17). A summary of the procedures has been provided here. For education and economic status, difference was calculated as NMR in the 'uneducated' group minus NMR in the 'secondary education' group, and NMR in the poorest group minus NMR in the richest group, respectively. Relatedly, the difference between rural and urban populations was calculated for the place of residence. Difference for sex was calculated as male minus female and, for subnational regions, the difference between the region with the highest estimate and the region with the lowest estimate was calculated. The calculation of ratio parallels that of difference, except that we divided one estimate by the estimate of another, instead of taking the difference between groups.

PAR was calculated as the difference between the estimate of NMR for the reference subgroup, yref and the national average of the NMR. For ordered dimensions, the most advantaged subgroup describes yref. For binary dimensions, such as sex, yref refers to a subgroup with the lowest estimate. In our case, the subgroup with the lowest estimate for sex was female. For non-ordered dimensions, such as the subnational region, yref refers to the subgroup or region with the lowest estimate. PAF was calculated by dividing the PAR by the national average $\mu$ and multiplying the fraction by 100 $[\mathrm{PAF}=(\mathrm{PAR} / \mu) \times 100]$. A higher absolute value of PAR and PAF is an indication of a higher level of inequality, whereas 0 indicates the lack of inequality. We examined the change in NMR over time by reference to $95 \%$ of the uncertainty intervals (UIs). Absence of an overlap in UIs implies a statistically significant difference between the two UIs. Absence of inequality occurs when the UIs overlap $(17,21)$. The complex and multi-stage nature of the data has been taken into account during analysis to produce non-biased and representative findings at the national level.

\section{Ethical consideration}

Analyses were completed using publicly available data from demographic health surveys. Ethical procedures were the responsibility of the institutions that commissioned, financed or managed the studies. All DHS surveys are approved by the ICF International and the institutional review board in the respective country to ensure that the protocols comply with the USA.

\section{Results}

A total population of 24124 were involved in this study. Of them, $12019(49.8 \%), 9388(38.9 \%)$ and $5241(21.7 \%)$ were females, rural residents and among the Quintile 1 subgroups, respectively. Regarding educational status, $9859(40.8 \%)$ had primary school education, followed by $7422(30.7 \%)$ of no educated subgroups.

Table 1 shows the magnitude of the NMR across socio-economic subgroups in Angola in 2015. The national average newborn mortality rate in Angola in 2015 was 24.1 deaths per 1000 live births. There were NMR disparities across socio-economic and area-based subgroups, namely economic, educational status, place of residence, sex and subnational region with high mortality among the disadvantaged subpopulations. For instance, of all wealth quintiles, the lowest NMR was observed among the richest quintile and lowest in the other categories (Fig. 1 and Table 1).

NMR also varied across educational subgroups with widening difference between primary and secondary school and above subgroups (Fig. 2). For instance, NMR among primary school subgroups was $30.1 \%$ [ $95 \%$ confidence interval (CI): 25.16, 36.08], whereas, among the secondary school and above, it was $18.7 \%$ (95\% CI: 14.39, 24.29) (Table 1).

There was a significant difference in NMR based on the place of residence with a higher mortality rate among rural residents (Fig. 3). The current study shows the presence of neonatal mortality differences based on child sex with significantly higher mortality among male children (Table 1).

Similarly, a subnational regional difference in NMR was observed in Angola in 2015. For instance, the lowest NMR was observed in Moxico $(4.2 \%$; $95 \%$ CI: $1.47,12.38)$ and the highest was in Benguela (48.2\%; 95\% CI: 37.08, 62.49; Table 1).

\section{Extents of socio-economic and area-based inequality}

Table 2 shows the extents of socio-economic and area-based inequality in NMR in 2015 with higher concentration among disadvantaged subgroups. Both simple and complex measures indicate substantial absolute (D and PAR) and relative ( $\mathrm{R}$ and PAF) wealthdriven inequality in NMR in 2015. For instance, the PAF measure $-58.5 \%$ (95\% CI: $-62.57,-54.58)$ confirmed significant relative economic inequality with higher burden among disadvantaged subgroups, such as weakest and poorest, as compared to advantaged subgroups, such as richest. Likewise, the D measure 20.98 (95\% CI; $12.54,29.42$ ) indicates significant absolute wealth-driven disparities in NMR with higher concentration among poorest subgroups than their counterparts (Table 2). 
Table 1. NMR across socio-economic and geographic area subgroups in Angola: evidence from 2015 Angola demographic health survey

\begin{tabular}{|c|c|c|c|}
\hline \multirow{2}{*}{$\begin{array}{l}\text { Dimension of } \\
\text { inequality }\end{array}$} & \multirow[t]{2}{*}{ Subgroup } & \multicolumn{2}{|l|}{2015} \\
\hline & & Estimate $(95 \% \mathrm{CI})$ & Pop $^{n}$ \\
\hline \multirow[t]{5}{*}{$\begin{array}{l}\text { Economic } \\
\text { status }\end{array}$} & $\begin{array}{l}\text { Quintile } 1 \\
\text { (poorest) }\end{array}$ & $30.99(24.73,38.78)$ & 5241 \\
\hline & Quintile 2 & $29.57(24.34,35.89)$ & 5565 \\
\hline & Quintile 3 & $21.32(15.91,28.52)$ & 5236 \\
\hline & Quintile 4 & $23.76(17.11,32.90)$ & 4619 \\
\hline & $\begin{array}{l}\text { Quintile } 5 \\
\text { (richest) }\end{array}$ & $10.01(6.20,16.11)$ & 3462 \\
\hline \multirow[t]{3}{*}{ Education } & No education & $21.26(17.21,26.25)$ & 7422 \\
\hline & Primary school & $30.14(25.16,36.08)$ & 9859 \\
\hline & $\begin{array}{l}\text { Secondary } \\
\text { school + }\end{array}$ & $18.71(14.39,24.29)$ & 6843 \\
\hline \multirow{4}{*}{$\begin{array}{l}\text { Place of } \\
\text { residence } \\
\text { Sex }\end{array}$} & Rural & $29.70(25.24,34.91)$ & 9388 \\
\hline & Urban & $20.65(16.98,25.09)$ & 14736 \\
\hline & Female & $18.53(15.18,22.59)$ & 12019 \\
\hline & Male & $29.77(25.52,34.70)$ & 12105 \\
\hline \multirow{19}{*}{$\begin{array}{l}\text { Subnational } \\
\text { region }\end{array}$} & 01 Cabinda & $14.75(8.04,26.90)$ & 458 \\
\hline & 02 Zaire & $16.71(9.70,28.65)$ & 498 \\
\hline & 03 Uige & $26.70(17.40,40.76)$ & 1385 \\
\hline & 04 Luanda & $15.15(10.49,21.85)$ & 7075 \\
\hline & 05 Cuanza norte & $35.66(24.68,51.29)$ & 328 \\
\hline & 06 Cuanza sul & $29.91(22.65,39.41)$ & 2022 \\
\hline & 07 Malanje & $21.24(12.35,36.31)$ & 956 \\
\hline & 08 Lunda norte & $17.18(9.82,29.89)$ & 701 \\
\hline & 09 Benguela & $48.22(37.08,62.49)$ & 2326 \\
\hline & 10 Huambo & $29.50(19.81,43.71)$ & 1966 \\
\hline & $11 \mathrm{Bie}$ & $15.87(9.51,26.34)$ & 1316 \\
\hline & 12 Moxico & $4.28(1.47,12.38)$ & 461 \\
\hline & 13 Cuando & $24.35(15.55,37.94)$ & 410 \\
\hline & Cubango & & \\
\hline & 14 Namibe & $25.51(19.42,33.46)$ & 306 \\
\hline & 15 Huila & $35.89(24.69,51.89)$ & 2300 \\
\hline & 16 Cunene & $21.18(10.72,41.43)$ & 885 \\
\hline & 17 Lunda sul & $9.31(5.26,16.42)$ & 473 \\
\hline & 18 Bengo & $10.26(4.30,24.27)$ & 251 \\
\hline $\begin{array}{l}\text { National } \\
\text { average }\end{array}$ & & 24.17397 & \\
\hline
\end{tabular}

Educational status inequality in neonatal mortality was observed with complex measures (PAF and PAR) but not by simple measures (D and R). For instance, the PAR measure -5.45 (95\% CI: -6.26, -4.65) signified significant absolute education-based disparities in NMR, with higher concentration among uneducated than educated subgroups (Table 2).

Regarding where the mothers lived, both the simple and complex measures indicated a significant place of residence inequality in NMR. The D measure 9.04 (95\% CI: 2.77, 15.32) pointed out significant absolute urban-rural disparity, with more neonatal mortality among disadvantaged subgroups (rural residents). Additionally, the PAF measure -14.56 (95\% CI: $-16.38,-12.74)$ tells us substantial relative urban-rural disparities in NMR with higher concentration among rural residents (Table 2).

Significant sex-based inequality in NMR with both simple (D and R) and complex (PAF and PAR) measures was also seen in 2015. For example, the PAF measure -23.34 (95\% CI: -25.55, -21.13) indicated significant relative sex-based inequality in NMR with higher concentration among male neonates. Similarly, the R measure 1.60
(95\% CI: 1.20, 2.00) indicated the significant relative sex-based disparity with higher-level among male neonates (Table 1).

Except by R measure, the current study showed huge subnational regional inequality in NMR in 2015 with all other three measures, namely D, PAR and PAF. For instance, the PAF measure -82.27 (95\% CI: -90.14, -74.41) indicated significant relative subnational regional inequality favouring the Moxico subregion (Table 2). For more detail of inequality, please see Table 2.

\section{Discussion}

To the best of our knowledge, this is the first attempt to explore the socio-economic, gender-based and geographic disparities in NMR in Angola comprehensively. We found a substantial pro-rich inequality in NMR in Angola in 2015. The D measure, for example, shows that the NMR among the poorest subpopulations was approximately 21 neonatal deaths per 1000 live births higher than the richest subpopulation. Similarly, the ratio shows that NMR among the poorest subpopulations was three times higher compared to the richest subgroups. The 2015 NMR of the country could be reduced by approximately 59 and 14 neonatal deaths per 1000 live births if relative and absolute wealth-related disparities were avoided, respectively. The findings are consistent with previous studies around the globe (22-25). The reason for higher NMR among the poorest subpopulations is the disparity in access to health care services and facilities between income groups (26).

The finding also suggests that the 2015 NMR could be reduced by approximately 23 and 5 neonatal deaths per 1000 live births if relative and absolute educational disparities were avoided, respectively. Consistent with previous studies (27-29), our findings also show a lower NMR among newborns born to educated mothers. This could be due to better birth spacing (i.e. longer birth intervals), better awareness and use of prenatal care and health services among educated mothers $(30,31)$.

The results of maternal education on neonatal/infant survival can be clarified in different areas (economic, social, demographic, environmental and biomedical) (31). Participation in higher education enables a woman to gain a better job and, thus, a higher income/wealth level (32). Maternal education can also influence mothers' attitudes towards traditional norms and beliefs, including traditional neonatal/ infant care practices, knowledge about illness and disease prevention practices that affect the survival of newborns, infants and children (33). Educated mothers are highly likely to use modern health care facilities and are more aware of sanitary activities (34). The level of education is a good proxy for the socio-economic position by improving the capacity to survive with the number of costs involved (35). Education is also likely to enhance female independence in order to increase women's confidence and ability to make choices about their own and their newborn's or children's health (36).

The $\mathrm{R}$ measure suggests that the NMR among rural residents was 1.4 times higher compared to urban residents. This finding is consistent with some previous studies confirming the pro-urban nature of NMR $(14,37)$. This could be due to worse birth outcomes in rural areas, as confirmed by studies conducted in other countries $(5,6,9)$. Some scholars have also explained that congenital malformation in the neonatal and post-neonatal periods has a higher risk of mortality in rural areas compared to cities identified by other authors (38). The causes of most congenital malformations have not yet been fully understood; however, their risk factors may be limited access to prenatal care $(39,40)$, occupational exposure to pesticides 


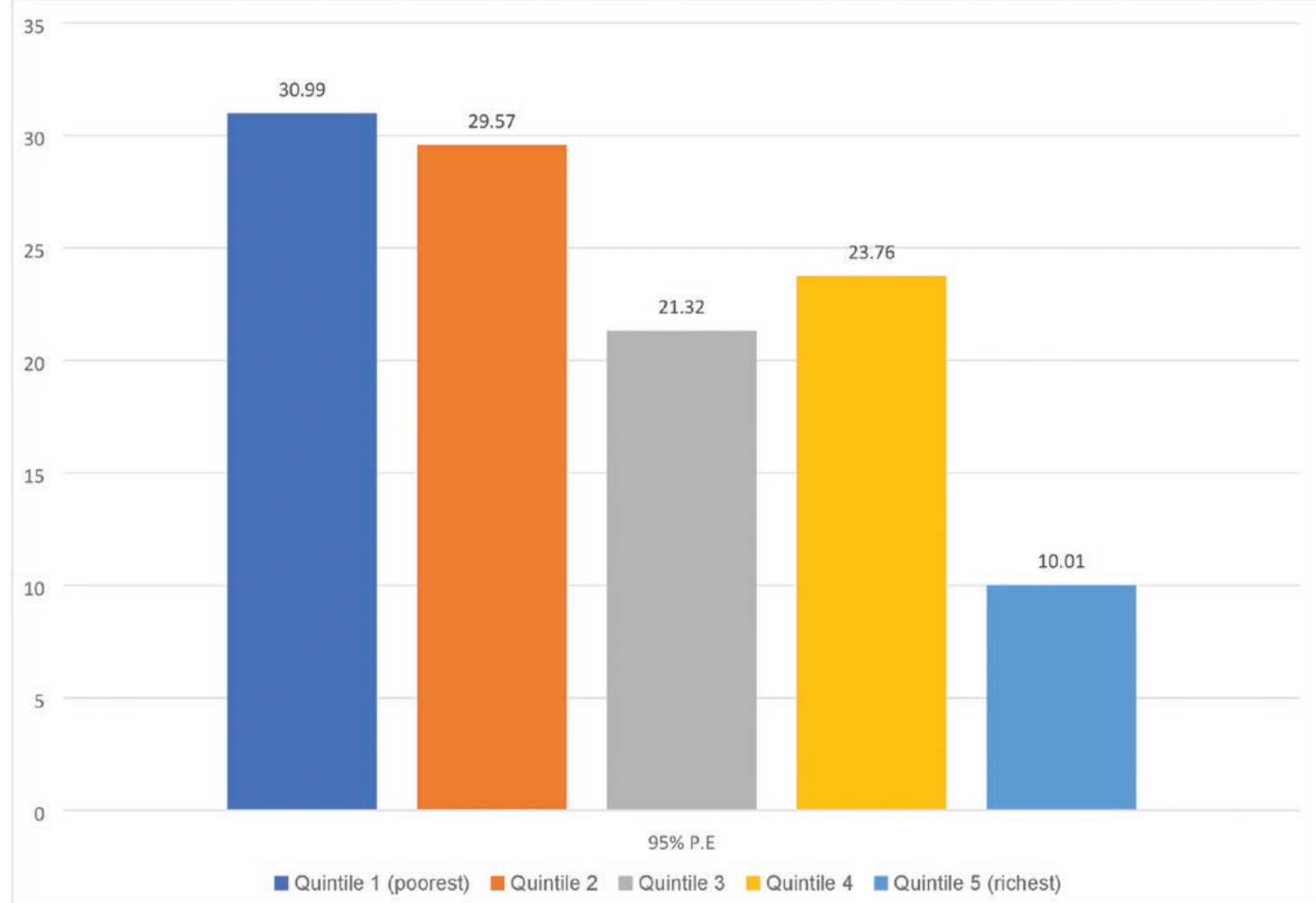

Figure 1. The magnitude of NMR across wealth quintiles in Angola in 2015.

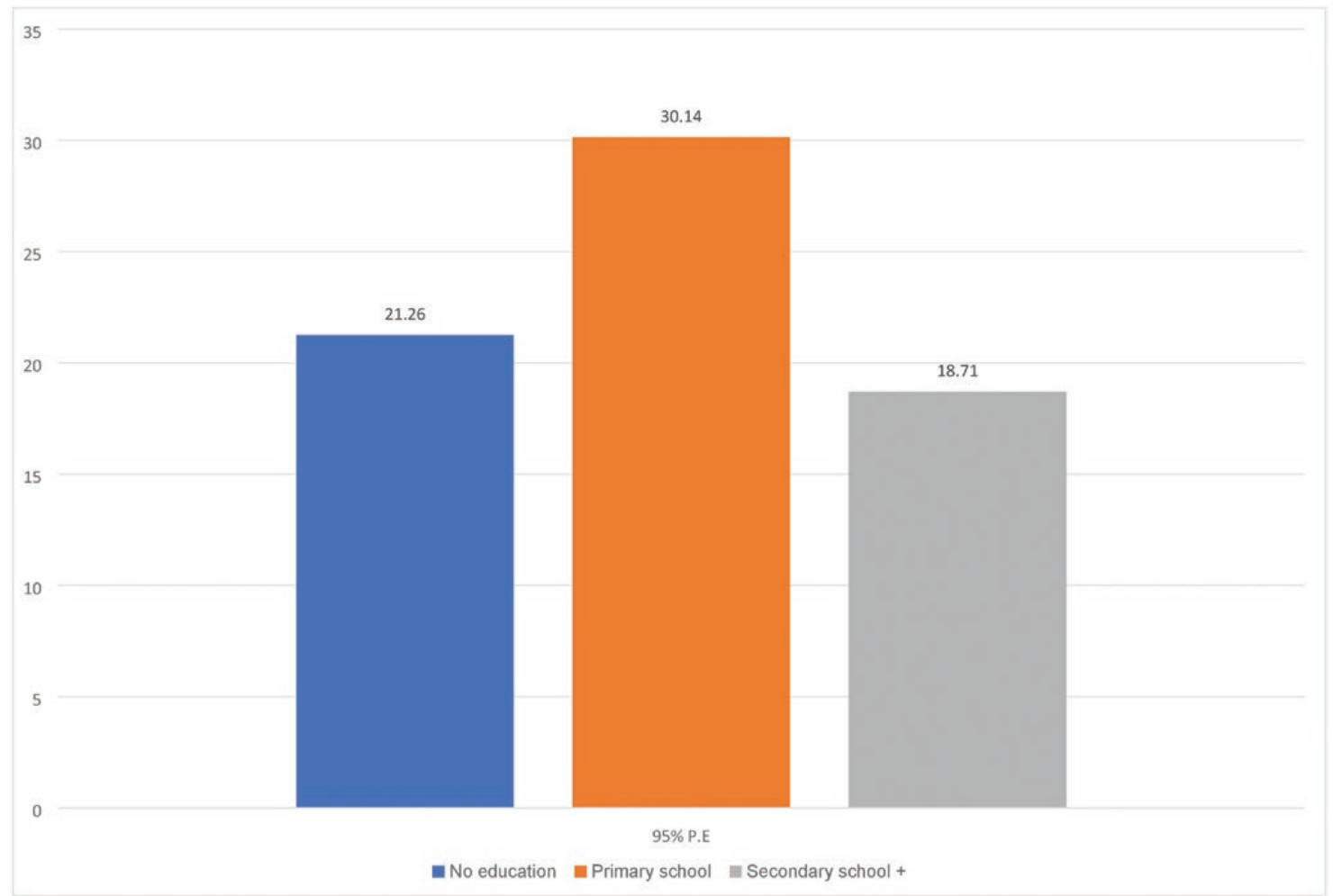

Figure 2. The magnitude of NMR across education subgroups in Angola in 2015. 


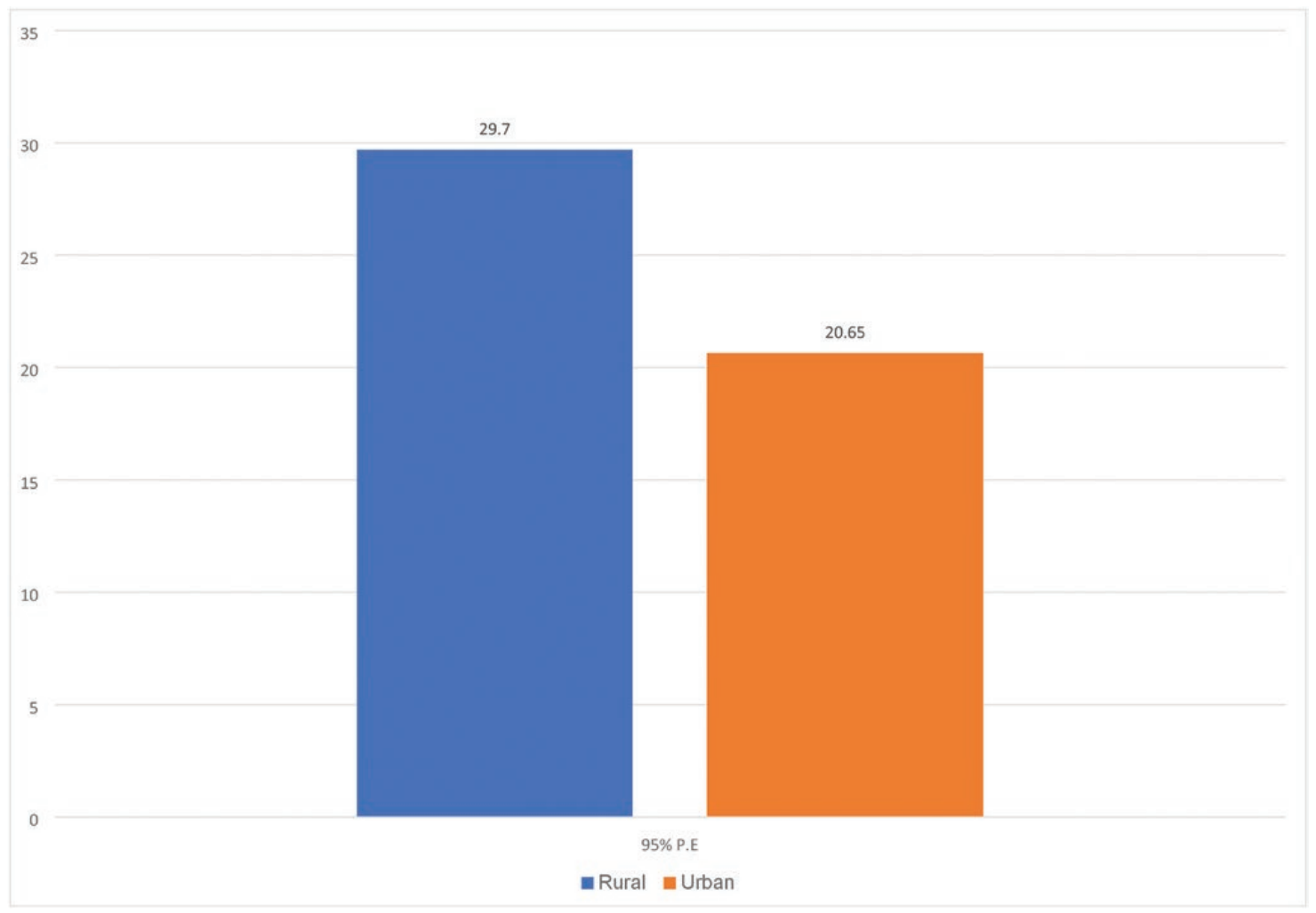

Figure 3. The magnitude of NMR by place of residence in Angola in 2015.

Table 2. The magnitude of socio-economic and area-based inequality in neonatal mortality rate in Angola: analysis of 2015 Angola demographic and health survey

\begin{tabular}{llc}
\hline Dimension of inequality & Measure type & 2015 \\
\cline { 3 - 3 } & & $\%(95 \%$ CI $)$ \\
\hline Economic status & D & $20.98(12.54,29.42)$ \\
& PAF & $-58.57(-62.57,-54.58)$ \\
& PAR & $-14.16(-15.12,-13.19)$ \\
Education & $\mathrm{R}$ & $3.09(1.46,4.72)$ \\
& $\mathrm{D}$ & $2.55(-4.07,9.18)$ \\
& PAF & $-22.58(-25.93,-19.23)$ \\
Place of residence & PAR & $-5.45(-6.26,-4.65)$ \\
& $\mathrm{R}$ & $1.13(0.75,1.51)$ \\
& $\mathrm{D}$ & $9.04(2.77,15.32)$ \\
Sex & PAF & $-14.56(-16.38,-12.74)$ \\
& PAR & $-3.52(-3.96,-3.08)$ \\
& $\mathrm{R}$ & $1.43(1.07,1.80)$ \\
& $\mathrm{D}$ & $11.24(5.38,17.10)$ \\
Subnational regions & PAF & $-23.34(-25.55,-21.13)$ \\
& PAR & $-5.64(-6.17,-5.10)$ \\
& $\mathrm{R}$ & $1.60(1.20,2.00)$ \\
& $\mathrm{D}$ & $43.94(30.56,57.31)$ \\
& PAF & $-82.27(-90.14,-74.41)$ \\
& PAR & $-19.89(-21.79,-17.98)$ \\
& $\mathrm{R}$ & $11.25(-1.07,23.59)$ \\
\hline
\end{tabular}

D, difference; R, ratio.

(41), low socio-economic status $(42,43)$ and barriers in access to obstetric and foetal diagnostics (44)

Substantial gender-based inequality in NMR was evident in Angola, favouring female neonates. The NMR among male neonates was 1.6 times higher compared to female neonates as measured by $\mathrm{R}$ (Table 2). This finding is consistent with a previous study, which showed that NMR was more prevalent among male children (45). Explanations for higher male neonatal mortality have been suggested in previous studies and hypothesized to be a "male disadvantage" suggesting that male sex appears to be more susceptible to mortality and morbidity, including low Apgar score, intrauterine growth restriction, respiratory failure or prematurity (45-47). Differences in pulmonary biomechanics and vascular development that lead to increased respiratory and neurological morbidity among preterm male neonates may also be a factor $(48,49)$. In addition, other studies have reported that preterm females have significantly higher catecholamine levels than preterm males, which have been identified as the essential defence mechanism used by hypoxic foetuses (50-52).

It should be noted that the 2015 NMR could be reduced by almost 82 and 20 neonatal deaths per 1000 live births while avoiding relative and absolute regional disparities. In addition, the $\mathrm{R}$ measure shows that the NMR in the Benguela region was 11 times higher than in Moxico. Possible reasons for the noticeable regional variance in NMR are a difference in the quality of available midwifery, obstetric and paediatric care $(10,11)$. In addition, differences in some health facilities and health personnel, ease or difficulty of inaccessibility to health services and some private health facilities in the regions can largely create disparities in the quality of health services, including pregnant women, across regions $(53,54)$. Previous studies found that, although high consumption of health services reduces neonatal, child and maternal mortality, regional disparities could be a barrier and can be explained by the difference in the accessibility of health care services and awareness of the use of antenatal care services $(55,56)$. 


\section{Strengths and limitations}

The first strength of this study is that a broader aspect of the dimensions of the disparities was assessed, leading the decision maker to see where they should focus and, once again, to reflect the output of the previous equity-focussed intervention. Second, NMR inequality has been assessed through a variety of summary measures, simple and complex, as well as relative and absolute summary measures, and this practice is useful in drawing all possible conclusions about NMR inequality. Finally, the findings are based on the established and published WHO Monitoring Database. The database was prepared by experts in the field who contributed to the quality of the evidence analysed and reported in this paper. However, the article did not identify the impact of a wide range of determinants on the measured NMR inequality. Future studies should use a decomposition approach to study factors that contribute to NMR inequality and see whether their contribution changes over time. In addition, variations in NMRs should be made in smaller areas, such as villages, towns, districts and zones, as ADHS data set findings cannot be applied to areas less than subnational regions and city administrations. Due to the unavailability of this data, we were unable to assess the trends of inequalities, and further studies may be needed to see changes over time.

\section{Conclusions}

We found a significant amount of NMR inequalities across the different equity stratifiers. Inequality studies such as this are useful to inform equity-oriented interventions aimed at eliminating inequalities; they signal affected subgroups to strategically target the plan and address the issue. Another implication of the findings is the need for the government of Angola and the Ministry of Health to enhance interventions, such as early initiation of breastfeeding, provision and promotion of the use of ITNs for children, improved antenatal care, delivery and postnatal care services with much focus on noneducated mothers, those with poor wealth status, those with male children, rural residents and residents in poor regions. Policymakers should give priority to subpopulations with the highest prevalence of NMR without ignoring the rest of the population.

\section{Acknowledgement}

We acknowledge the WHO for making the software available in the public domain for free.

\section{Declarations}

Funding: no funding was received for this work.

Ethical approval: ethics approval was not required since the data is available in the public domain.

Conflict of interest: the authors declare no competing interests.

Data availability: the data sets generated and/or analysed during the current study are available in the WHO's HEAT version 3.1 (https://www.who.int/ gho/health_equity/assessment_toolkit/en/).

\section{References}

1. Zakšek TŠ, Došler AJ, Mivšek AP, Petročnik P. Neonatal care in the first hour of life. In: Selected Topics in Neonatal Care. London, UK: IntechOpen, 2017.

2. United Nations Inter-agency Group for Child Mortality Estimation (UN IGME). Levels \& Trends in Child Mortality: Estimates Developed by the UN Inter-Agency Group for Child Mortality Estimation. New York: United Nations Children's Fund, 2019.
3. Degefa N, Diriba K, Girma T et al. Knowledge about neonatal danger signs and associated factors among mothers attending immunization clinic at Arba Minch General Hospital, Southern Ethiopia: a cross-sectional study. Biomed Res Int 2019; 2019: 9180314.

4. Lassi ZS, Middleton PF, Crowther C, Bhutta ZA. Interventions to improve neonatal health and later survival: an overview of systematic reviews. EBioMedicine 2015; 2(8): 985-1000.

5. Gyimah SO. A cohort analysis of the timing of first birth and fertility in Ghana. Population Research and Policy Review. 2003; 22(3): 251-66.

6. Tsala Dimbuene Z, Amo-Adjei J, Amugsi D et al. Women's education and utilization of maternal health services in Africa: a multi-country and socioeconomic status analysis. J Biosoc Sci 2018; 50(6): 725-48.

7. Black RE, Laxminarayan R, Temmerman M, Walker N (eds.). Reproductive, Maternal, Newborn, and Child Health: Disease Control Priorities, Vol. 2, 3rd edn. Washington, DC: The International Bank for Reconstruction and Development / The World Bank, 2016.

8. Kinney MV, Kerber KJ, Black RE et al.; Science in Action: Saving the Lives of Africa's Mothers, Newborns, and Children Working Group. Sub-Saharan Africa's mothers, newborns, and children: where and why do they die? PLoS Med 2010; 7(6): e1000294.

9. Günther I, Harttgen K. Deadly cities? Spatial inequalities in mortality in sub-Saharan Africa. Population Devel Rev 2012; 38(3): 469-86.

10. WHO. Country Profile: Angola [Internet]. 2020. https://www.who.int/had crises/ago/background/profile/en/ (accessed 3 June 2020).

11. WHO. WHO Country Cooperation Strategy. Angola. Geneva, Switzerland: WHO, 2018.

12. Rosário EVN, Gomes MC, Brito M, Costa D. Determinants of maternal health care and birth outcome in the Dande Health and Demographic Surveillance System area, Angola. PLoS One 2019; 14(8): e0221280.

13. Humbwavali JB, Giugliani C, Nunes LN, Dalcastagnê SV, Duncan BB. Malnutrition and its associated factors: a cross-sectional study with children under 2 years in a suburban area in Angola. BMC Public Health 2019; 19(1): 220.

14. Yaya S, Uthman OA, Okonofua F, Bishwajit G. Decomposing the ruralurban gap in the factors of under-five mortality in sub-Saharan Africa? Evidence from 35 countries. BMC Public Health 2019; 19(1): 616.

15. Bendavid E. Changes in child mortality over time across the wealth gradient in less-developed countries. Pediatrics 2014; 134(6): e1551-9.

16. Mosley WH, Chen LC. An analytical framework for the study of child survival in developing countries. Population Devel Rev 1984; 10: 25-45.

17. WHO. Handbook on Health Inequality Monitoring: With a Special Focus on Low- and Middle-Income Countries. Geneva, Switzerland: WHO, 2013.

18. National Statistics Institute (INE), Ministry of Health (MINSA), Ministry of Planning and Development Territorial Development (MINPLAN), ICF. Multiple Indicators and Health Survey in Angola 2015-2016. Luanda, Angola; Rockville, MD: INE; MINSA; MINPLAN; ICF, 2017.

19. Bobo FT, Yesuf EA, Woldie M. Inequities in utilization of reproductive and maternal health services in Ethiopia. Int J Equity Health 2017; 16(1): 105.

20. Van Malderen C, Amouzou A, Barros AJD et al. Socioeconomic factors contributing to under-five mortality in sub-Saharan Africa: a decomposition analysis. BMC Public Health 2019; 19(1): 760.

21. WHO. Health Equity Assessment Toolkit (HEAT): Software for Exploring and Comparing Health Inequalities in Countries. http:// bmcmedresmethodol.biomedcentral.com.proxy.bib.uottawa.ca/articles/10.1186/s12874-016-0229-9\%3e\%3e (accessed 3 May 2020).

22. Bado AR, Susuman AS. Women's education and health inequalities in under-five mortality in selected sub-Saharan African countries, 19902015. PLoS One 2016; 11(7):e0159186.

23. Kanmiki EW, Bawah AA, Agorinya I et al. Socio-economic and demographic determinants of under-five mortality in rural northern Ghana. BMC Int Health Hum Rights 2014; 14: 24.

24. Khajavi A, Pishgar F, Dehghani M, Naderimagham S. Socioeconomic inequalities in neonatal and postneonatal mortality: evidence from rural Iran, 1998-2013. Int J Equity Health 2017; 16(1): 83.

25. McKinnon B, Harper S, Kaufman JS, Bergevin Y. Socioeconomic inequality in neonatal mortality in countries of low and middle income: a multicountry analysis. Lancet Glob Health 2014; 2(3): e165-73. 
26. Schramm G. The Effects Race and Socioeconomic Status Have on Infant Mortality Rates [Honors Research Projects]. Akron, OH: The University of Akron, 2016.

27. Asamoah BO, Agardh A, Pettersson KO, Östergren PO. Magnitude and trends of inequalities in antenatal care and delivery under skilled care among different socio-demographic groups in Ghana from 1988-2008. BMC Pregnancy Childbirth 2014; 14: 295.

28. Kiross GT, Chojenta C, Barker D, Tiruye TY, Loxton D. The effect of maternal education on infant mortality in Ethiopia: a systematic review and meta-analysis. PLoS One 2019; 14(7): e0220076.

29. Green T, Hamilton TG. Maternal educational attainment and infant mortality in the United States. Demographic Res 2019; 41: 713-52.

30. Heaman MI, Sword W, Elliott L et al. Barriers and facilitators related to use of prenatal care by inner-city women: perceptions of health care providers. BMC Pregnancy Childbirth 2015; 15: 2.

31. Vikram K, Desai S, Vanneman R. Maternal Education and Child Mortality: Exploring the Pathways of Influence. College Park, MD: University of Maryland, 2010.

32. Aslam M, Kingdon GG. Parental education and child health-understanding the pathways of impact in Pakistan. World Devel 2012; 40(10): 2014-32.

33. Bicego GT, Boerma JT. Maternal education and child survival: a comparative study of survey data from 17 countries. Soc Sci Med 1993; 36(9): 1207-27.

34. Fatema SR, Kabir MH. Maternal education, hygienic practices and children's health status. EPH Int J Med Health Sci 2017; 3(7): 1-13.

35. Zyaambo C, Siziya S, Fylkesnes K. Health status and socio-economic factors associated with health facility utilization in rural and urban areas in Zambia. BMC Health Serv Res 2012; 12: 389.

36. Chen E, Matthews KA, Boyce WT. Socioeconomic differences in children's health: how and why do these relationships change with age? Psychol Bull 2002; 128(2): 295-329.

37. Yi B, Wu L, Liu H et al. Rural-urban differences of neonatal mortality in a poorly developed province of China. BMC Public Health 2011; 11: 477 .

38. Bocquier P, Madise NJ, Zulu EM. Is there an urban advantage in child survival in sub-Saharan Africa? Evidence from 18 countries in the 1990s. Demography 2011; 48(2): 531-58.

39. Kamla I, Kamgaing N, Billong S et al. Antenatal and postnatal diagnoses of visible congenital malformations in a sub-Saharan African setting: a prospective multicenter cohort study. BMC Pediatr 2019; 19(1): 457.

40. Yaya S, Bishwajit G, Ekholuenetale M, Shah V. Inadequate utilization of prenatal care services, socioeconomic status, and educational attainment are associated with low birth weight in Zimbabwe. Front Public Health 2017; 5: 35 .

41. Ueker ME, Silva VM, Moi GP et al. Parenteral exposure to pesticides and occurence of congenital malformations: hospital-based case-control study. BMC Pediatr 2016; 16(1): 125.

42. Rosano A, Del Bufalo E, Burgio A. [Socioeconomic status and risk of congenital malformations]. Epidemiol Prev 2008; 32(1): 21-6.

43. Vrijheid M, Dolk H, Stone D et al. Socioeconomic inequalities in risk of congenital anomaly. Arch Dis Child 2000; 82(5): 349-52.

44. Pinto NM, Keenan HT, Minich LL et al. Barriers to prenatal detection of congenital heart disease: a population-based study. Ultrasound Obstet Gynecol 2012; 40(4): 418-25.

45. Yaya S, Diarra S, Mabeu MC, Pongou R. The sex gap in neonatal mortality and the AIDS epidemic in sub-Saharan Africa. BMJ Glob Health 2018; 3(5): e000940.

46. Tabutin D, Masquelier B, Grieve M, Reeve P. Mortality inequalities and trends in low- and middle-income countries, 1990-2015. Population 2017; 72(2): 221-96.

47. Zhao D, Feng X, Zhu X et al. CRISPR/Cas9-assisted gRNA-free one-step genome editing with no sequence limitations and improved targeting efficiency. Sci Rep 2017; 7(1): 16624.

48. Malhotra A, Allison BJ, Castillo-Melendez M et al. Neonatal morbidities of fetal growth restriction: pathophysiology and impact. Front Endocrinol (Lausanne) 2019; 10: 55.

49. Baerg J, Thirumoorthi A, Hopper A. Respiratory management of the newborn with an omphalocele. In: Respiratory Management of Newborns. London, UK: IntechOpen, 2016.

50. Ingemarsson I. Gender aspects of preterm birth. BJOG 2003; 110(Suppl 20): $34-8$.

51. Di Renzo GC, Rosati A, Sarti RD, Cruciani L, Cutuli AM. Does fetal sex affect pregnancy outcome? Gend Med 2007; 4(1): 19-30.

52. O'Driscoll DN, McGovern M, Greene CM, Molloy EJ. Gender disparities in preterm neonatal outcomes. Acta Paediatr 2018; 107(9): 1494-9.

53. National Academies of Sciences, Engineering, and Medicine. Health-Care Utilization as a Proxy in Disability Determination. Washington, DC: National Academies Press, 2018.

54. Frøystad M, Mæstad O, Villamil N. Health services in Angola. Availability, quality and utilisation. CMI Report. 2011; 2011(9), 66pp.

55. Pandey S, Karki S. Socio-economic and demographic determinants of antenatal care services utilization in central Nepal. Int J MCH AIDS 2014; 2(2): 212-9.

56. Tekelab T, Chojenta C, Smith R, Loxton D. The impact of antenatal care on neonatal mortality in sub-Saharan Africa: a systematic review and meta-analysis. PLoS One 2019; 14(9): e0222566. 